\title{
Successful treatment of ball-shaped very late thrombus after myocardial infarction
}

\author{
Toru Inami, ${ }^{1}$ Masafumi Tsurumi, ${ }^{1}$ Yoshihiko Seino, ${ }^{1}$ Wataru Shimizu ${ }^{2}$
}

${ }^{1}$ Cardiovascular Centre, Nippon Medical School, Chiba Hokusoh Hospital, Chiba, Japan

${ }^{2}$ Department of Cardiovascular Medicine, Nippon Medical School, Tokyo, Japan

\section{Correspondence to} Dr Toru Inami, t-inami@nms.ac.jp

Accepted 16 April 2014
CrossMark

To cite: Inami T, Tsurumi M, Seino Y, et al. BMJ Case Rep Published online: [please include Day Month Year] doi:10.1136/ bcr-2014-204340

\section{DESCRIPTION}

A 40-year-old man presented with chest pain. Eight years ago he had suffered from acute anteroseptal ST-elevation myocardial infarction (MI) and 3 years ago he stopped taking medicines including antiplatelet drugs and warfarin by himself. ECG showed no ST-elevation this time; however, elevation of troponin T was detected, which diagnosed a second attack of MI. Emergent coronary angiography showed total occlusion of previously deployed stent in the left ascending coronary artery. His conventional coronary risk factors were smoking and dyslipidaemia. Transthoracic echocardiography revealed a huge pedunculated, oscillating mass at the left ventricular (LV) apex (figure $1 \mathrm{~A}$, video 1 ), which had not been detected during the first admission. The echotexture is heterogeneous with pulsatile partial change of morphology. The size of the mass was $42 \times 26 \mathrm{~mm}$. Cardiac MRI also documented a mass at the apex (figure 1B). Three weeks after initiation of the recommended anticoagulant therapy including unfractionated heparin and warfarin, ${ }^{1}$ echocardiography showed the completely vanishing mass and none of apical aneurysmal changes (figure 1C, video 2). Differential diagnosis of ball-shaped mass in the LV may be thrombi, tumours or vegetations. Disappearance by anticoagulation therapy gave definitive diagnosis of thrombus. The incidence of $\mathrm{LV}$ thrombus was about $4 \%$ in patients with segment elevation MI (STEMI) treated with percutaneous intervention. ${ }^{2}$ Most of LV thrombi are mural thrombi

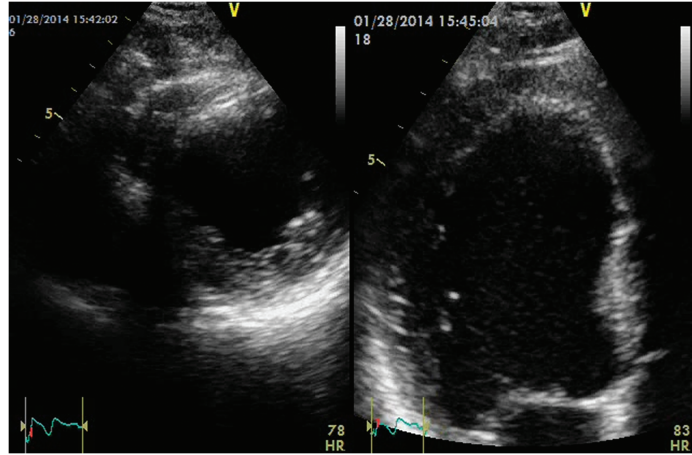

Video 1 Transthoracic echocardiography revealed huge pedunculated oscillating mass at the left ventricular apex.

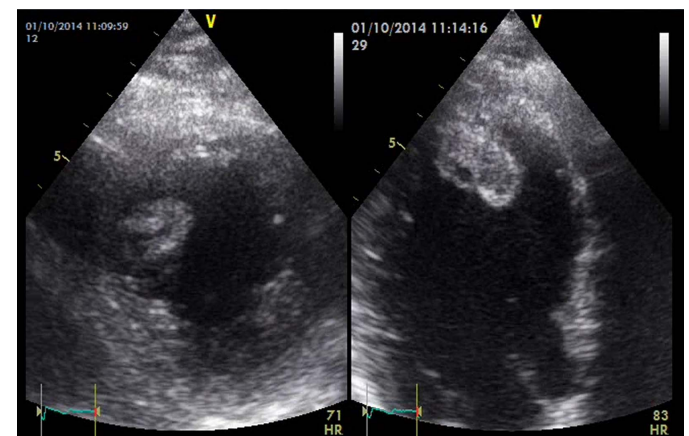

Video 2 Echocardiography after the initiation of anticoagulant therapy showed the completely vanished mass and none of apical aneurysmal change.
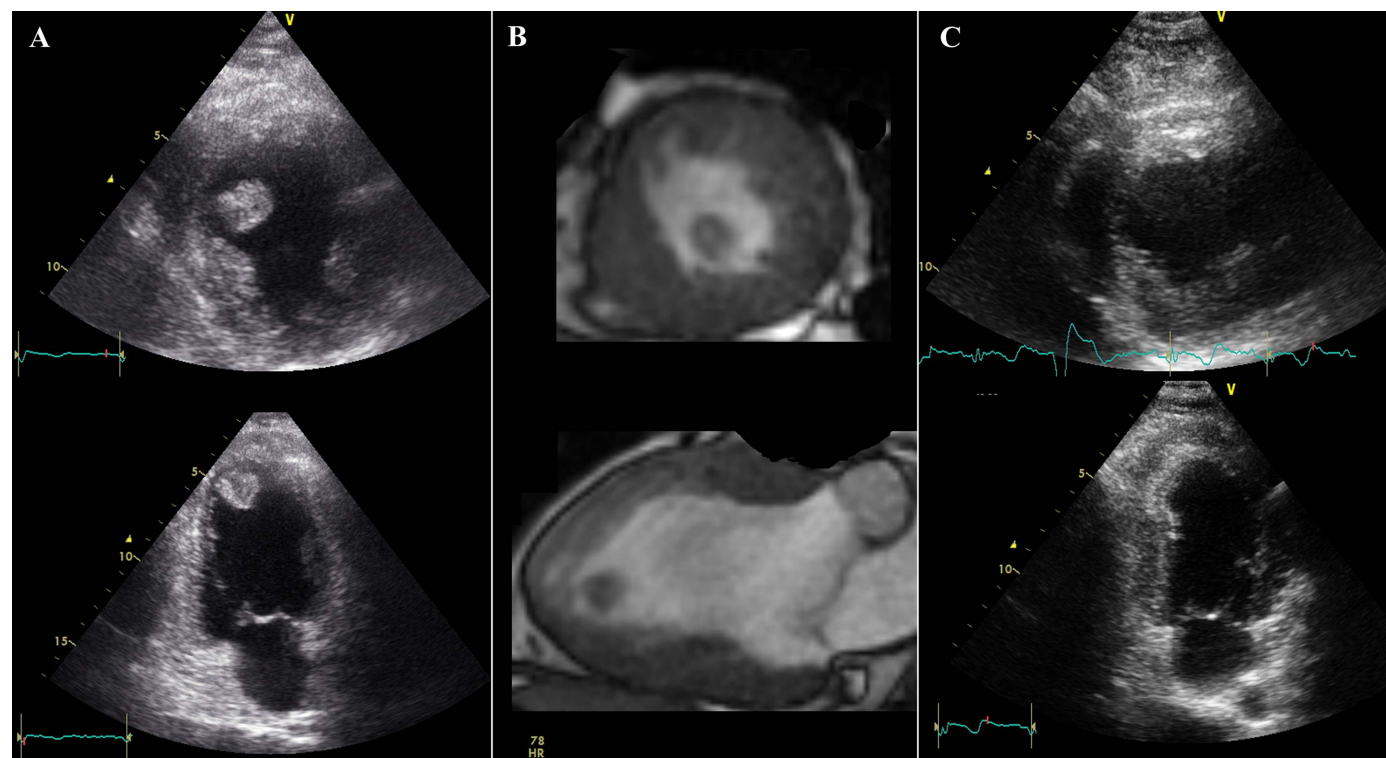

Figure 1 (A) Transthoracic echocardiography revealed a huge pedunculated oscillating mass at the left ventricular apex. (B) Cardiac MRI documented movable mass at the apex. (C) Echocardiography after the initiation of anticoagulant therapy showed the completely vanished mass and none of the apical aneurysmal change. 
significantly increasing the risk of embolisation. LV thrombi after an acute anterior MI were present in $96 \%$ at 2 weeks. ${ }^{3}$ Few thrombi developed several years after MI. This is a very rare case that the ball-shaped pedunculated thrombus developed very late in the LV apex 8 years after MI. Practical physicians should consider the possible existence of very late LV thrombus in patients with anteroseptal MI, and periodic echocardiography should be performed during long-term follow-up period.

\section{Learning points}

- Ball-shaped very late thrombus could develop in the left ventricular (LV) apex several years after myocardial infarction (MI).

- Periodic echocardiography in patients with anteroseptal MI should be performed during long-term follow-up period.

- Ball-shaped very late thrombus in left ventricular apex could disappear with the anticoagulant therapy.
Contributors IT, SY and SW contributed equally to the preparation and writing of the manuscript. TM contributed to treating patient in the intensive care unit.

Competing interests None.

Patient consent Obtained.

Provenance and peer review Not commissioned; externally peer reviewed.

\section{REFERENCES}

1 Vandvik PO, Lincoff AM, Gore JM, et al. Primary and secondary prevention of cardiovascular disease: antithrombotic therapy and prevention of thrombosis, 9th ed: American College of Chest Physicians Evidence-Based Clinical Practice Guidelines. Chest 2012;141:e637S-68S.

2 Gianstefani S, Douiri A, Delithanasis I, et al. Incidence and predictors of early left ventricular thrombus after ST-elevation myocardial infarction in the contemporary era of primary percutaneous coronary intervention. Am J Cardiol 2014;113:1111-16.

3 Kupper AJ, Verheugt FW, Peels $\mathrm{CH}$, et al. Left ventricular thrombus incidence and behavior studied by serial two-dimensional echocardiography in acute anterior myocardial infarction: left ventricular wall motion, systemic embolism and oral anticoagulation. J Am Coll Cardiol 1989;13:1514-20.

Copyright 2014 BMJ Publishing Group. All rights reserved. For permission to reuse any of this content visit http://group.bmj.com/group/rights-licensing/permissions.

BMJ Case Report Fellows may re-use this article for personal use and teaching without any further permission.

Become a Fellow of BMJ Case Reports today and you can:

- Submit as many cases as you like

- Enjoy fast sympathetic peer review and rapid publication of accepted articles

- Access all the published articles

- Re-use any of the published material for personal use and teaching without further permission

For information on Institutional Fellowships contact consortiasales@bmjgroup.com

Visit casereports.bmj.com for more articles like this and to become a Fellow 